\title{
Association of Platelet Lymphocyte Ratio (PLR) and Neutrophil Lymphocyte Ratio (NLR) with Global Registry of Acute Coronary Events (GRACE) Score in Acute Coronary Syndrome
}

\author{
Baginda Yusuf Siregar ${ }^{1}$, Refli Hasan $^{2}$, Rahmad Isnanta $^{2}$ \\ ${ }^{1}$ Department of Internal Medicine, Faculty of Medicine, Universitas Sumatera Utara, Medan, Indonesia \\ ${ }^{2}$ Division of Cardiovascular, Department of Internal Medicine, Faculty of Medicine, Universitas Sumatera Utara \\ Corresponding Author: Baginda Yusuf Siregar
}

\begin{abstract}
Introduction: Acute Coronary Syndrome (ACS) has morbidity and mortality significantly increase, it requires risk stratification for the assessment and selection of initial invasive strategies. The Global Registry of Acute Coronary Events (GRACE) scores recommended as risk stratification of ACS. Some of studies found that the combination of GRACE scores with other clinical and laboratory parameters can increase predictive value of ACS. Platelet Lymphocyte Ratio (PLR) and Neutrophil Lymphocyte Ratio (NLR) act as parameter of systemic inflammation in ACS. Aims of the study to determine the association between PLR and NLR with risk stratification GRACE score.
\end{abstract}

Method: This study is analytical with a crosssectional retrospective design. This study included 70 patients with a diagnosis of ACS based on medical record data. Data analysis was performed using the Statistical Package for the Social Sciences (SPSS) 22.0. P-value $<0.05$ was considered statistically significant.

Results: This study was found a positive correlation between PLR and NLR with the GRACE score of patients ACS ( $\mathrm{r}=0.485$, $\mathrm{p}<0.001 ; \mathrm{r}=0.570, \mathrm{p}<0.001)$. The PLR and NLR were both found the significantly higher in the high risk GRACE score respectively $(188 \pm 47$, $\mathrm{p}<0.001 ; 7.9 \pm 2.7, \mathrm{p}<0.001)$. The ROC curve analysis, cutt-off PLR of 123 and above (sensitivity of $72.7 \%$; specificity of 70.3), while cutt-off NLR of 4 and above (sensitivity of
$78.8 \%$; specificity of $70.3 \%$ ) to detect high risk GRACE score.

Conclusion: There is a significant association between PLR and NLR with GRACE score

Keywords: Platelet Lymphocyte Ratio,

Neutrophil Lymphocyte Ratio, GRACE score,

Acute Coronary Syndrome

\section{INTRODUCTION}

The major cause of mortality globally is cardiovascular disease. Globally the mortality rate to cardiovascular disease reach 17.8 million, data of the American Heart Association (AHA). ${ }^{[1]}$ This mortality rates estimated increase reach 24.2 million by 2030 . There are 400.000 people die every year cause of ACS. ${ }^{[2]}$ In Indonesia found 15 out of 1,000 Indonesians suffer from coronary heart disease according to basic health research data in $2018 .^{[3]}$

ACS has morbidity and mortality significantly increased, it requires risk stratification for the assessment and selection of initial invasive strategies, find the best strategy for achieving and maintaining myocardial reperfusion. ${ }^{[4][5]}$ GRACE score is recommended for risk stratification and assessing the prognosis of ACS. ${ }^{[6]}$ High risk stratification of GRACE score recommended for an invasive strategy, while low risk stratification of GRACE score conservative approaches for ACS patients. ${ }^{[7]}$ 
Acute Coronary Syndrome is associated with rupture of atherosclerotic plaques and partial or complete thrombotic processes in arterial blood vessels. Inflammation has an important role in the initiation of atherosclerosis until rupture occurs causing ACS. ${ }^{[2]}$ Currently, neutrophil lymphocyte ratio (NLR) is accepted as parameter of systemic inflammation in ACS. High neutrophil levels, which reflect inflammation and low lymphocyte levels, which reflect physiological stress. ${ }^{[8]}$

The increase in platelet count reflects an inflammatory response. Platelets can release thromboxane and other mediators, increase adhesion and transmigration of monocytes, which can lead to increased inflammation and weaken plaque stability, then promote the development of atherosclerosis. ${ }^{\text {[9] }}$ Platelet Lymphocyte Ratio (PLR) is reflects of inflammation and the aggregation pathway as predictor atherosclerosis in ACS. ${ }^{[10]}$

Some of studies found that the combination of GRACE score with other clinical and laboratory parameters can increase predictive value of ACS. ${ }^{[11]}$ The Study of Zhou, found the combination of PLR and GRACE score was more effective in predicting incidence of ACS patients. ${ }^{[12]}$ Study of Acet et al, also found that high NLR was significantly with increased stratification of GRACE score. ${ }^{[13]}$ Aims of the study to determine the association and cut-off value PLR and NLR with risk stratification of GRACE score of ACS patients.

\section{METHODS}

This study is analytical with a crosssectional retrospective design. This study included 70 patients with a diagnosis of acute coronary syndrome based on medical record of RSUP Haji Adam Malik Medan from January 2019 to December 2019.

Subject of study were included if there is following criteria: patients with a diagnosis of ACS either ST elevation acute myocardial infarction (STEMI), non-ST elevation acute myocardial infarction
(NSTEMI) or unstable angina (UA) that was clinically confirmed through presence of ischemic symptoms with ECG changes consistent with ischemia based on medical records data. There is data of neutrophils, lymphocytes and platelets examined laboratory result then calculating PLR and NLR. Data of patients were stratified according to the GRACE score into stratification low risk $(<109)$, intermediaterisk (109-140) and high risk (>140).

\section{Exclusion Criteria}

If the medical record data is incomplete. Patients who had a clinically active infection, malignancy, hematological disorders including all types of anemia and hematological malignancies, blood transfusion, severe liver disease, active or chronic autoimmune disease, patients on steroid therapy or chemotherapy were excluded.

\section{Statistical Analysis}

Data analysis was performed using the Statistical Package for the Social Sciences (SPSS) 22.0 software. Numerical variables were presented as mean and standard deviation. Categorical variables were presented as percentages. Data were tested for normal distribution; differences between parametric quantitative independent groups were assessed by One way ANOVA test. The bivariate analysis using the Spearman correlation test. P-value $<0.05$ was considered statistically significant. Receiver Operating Characteristic (ROC) curve was used to determinate the optimal cut-off value as well as sensitivity and specificity.

\section{RESULT}

There are total 70 medical records data of ACS patients in this study. The characteristics subject of study such as age, gender, BMI, risk factors of cardiovascular, type of ACS and stratification of GRACE score are shown in (Table 1). The mean age of patient was $55.5 \pm 10.8$ years; this study included $65(92.9 \%)$ male, 58(82.9\%) smokers and 42 (60\%) patients 
hypertension. There were 47 (67.1\%) patients with STEMI and $21(30 \%)$ with NSTEMI.

The means of complete blood count parameter were compared between low, intermediate and high-risk GRACE score patients as shown in (Table 2). The mean of PLR and NLR statistically significant highest in the high-risk of GRACE score, while mean of lymphocyte count was highest in low risk of GRACE score (188 \pm $47 ; \quad 7.9 \pm 2.7 ; \quad 2.5 \pm 0.7, \quad \mathrm{p}=0.001$; respectively). There was found a positive correlation of PLR and NLR with GRACE score $(\mathrm{r}=0.485, \mathrm{r}=0.570, \mathrm{p}<0.001$; respectively) (Table 3 ).

Table 1: Characteristic of the study

\begin{tabular}{|l|c|}
\hline \multicolumn{1}{|c|}{ Variable } & $\mathbf{n}=\mathbf{7 0}$ \\
\hline Age, Mean \pm SD, years & $55.5 \pm 10.8$ \\
\hline Male, $\mathrm{n}(\%)$ & $65(92.9)$ \\
\hline BMI, Mean \pm SD, $\mathrm{kg} / \mathrm{m}^{2}$ & $26.7 \pm 3.9$ \\
\hline Hypertension, n (\%) & $42(60)$ \\
\hline DM, n (\%) & $17(24.3)$ \\
\hline Dyslipidemia, n (\%) & $22(31.4)$ \\
\hline Smoke, n (\%) & $58(82.9)$ \\
\hline STEMI, n (\%) & $47(67.1)$ \\
\hline NSTEMI, n (\%) & $21(30)$ \\
\hline UA, n (\%) & $2(2.9)$ \\
\hline Stratification of GRACE Score & \\
\hline Low risk, n (\%) & $37(52.9)$ \\
\hline Intermediate risk, $\mathrm{n}(\%)$ & $23(32.9)$ \\
\hline High risk, $\mathrm{n}(\%)$ & $10(14.3)$ \\
\hline
\end{tabular}

BMI: Body Mass Index; DM: Diabetes Mellitus; STEMI: ST Elevation Myocardial Infarction; NSTEMI: Non ST Elevation Myocardial Infarction; UA: Unstable Angina

Table 2: Comparison of the Complete Blood Count value between stratification risk of GRACE Score

\begin{tabular}{|c|c|c|c|c|c|}
\hline Variable & $\begin{array}{c}\text { Total }(\mathrm{N}=70) \\
\mathrm{X} \pm \mathrm{SD}\end{array}$ & $\begin{array}{c}\text { Low Risk }(\mathbf{N}=37) \\
\text { X } \pm \text { SD }\end{array}$ & $\begin{array}{c}\text { Intermediate Risk }(\mathbf{N}=23) \\
\mathrm{X} \pm \text { SD }\end{array}$ & $\begin{array}{c}\text { High Risk }(\mathbf{N}=10) \\
\mathrm{X} \pm \mathrm{SD}\end{array}$ & P-value \\
\hline WBC count, cells/mL & $11743 \pm 3443$ & $12411 \pm 3194$ & $11041 \pm 3676$ & $10885 \pm 3623$ & 0.23 \\
\hline Platelet $\left(10^{3} \mathrm{sel} / \mathrm{mm}^{3}\right)$ & $256 \pm 70$ & $271 \pm 60$ & $247 \pm 83$ & $225 \pm 63$ & 0.13 \\
\hline Neutrophil count & $8.5 \pm 2.97$ & $8.5 \pm 3.2$ & $7.9 \pm 2.7$ & $9.5 \pm 2.4$ & 0.38 \\
\hline Lymphocyte count & $2.1 \pm 0.8$ & $2.5 \pm 0.7^{\mathrm{a}, \mathrm{b}}$ & $1.7 \pm 0.6$ & $1.3 \pm 0.4$ & $0.001^{* *}$ \\
\hline PLR & $136 \pm 51$ & $114.4 \pm 37^{\mathrm{a}, \mathrm{b}}$ & $148 \pm 53$ & $188 \pm 47$ & $0.001^{* *}$ \\
\hline NLR & $4.7 \pm 2.5$ & $3.64 \pm 1.7^{\mathrm{a}, \mathrm{b}}$ & $5.23 \pm 2.33^{\mathrm{b}}$ & $7.9 \pm 2.7$ & $0.001^{* *}$ \\
\hline
\end{tabular}

WBC: White Blood Cell; PLR: Platelet Lymphocyte Ratio; NLR: Neutrophil Lymphocyte Ratio

Table 3: Correlation between PLR and NLR with the GRACE Score

\begin{tabular}{|c|c|c|}
\hline Spearman correlation & GRACE Score & P-value \\
\hline & $\mathbf{r}$ & \\
\hline PLR & 0.485 & $<0.001$ \\
\hline NLR & 0.570 & $<0.001$ \\
\hline
\end{tabular}

PLR: Platelet Lymphocyte Ratio; NLR: Neutrophyl Lymphocyte Ratio

Table 4: ROC curve analysis showing the area under the curve for PLR and NLR with sensitivity and specificity in diagnose stratification of GRACE score

\begin{tabular}{|c|c|c|c|c|} 
& $\begin{array}{c}\text { Cutt-off } \\
\text { value }\end{array}$ & AUC & $\begin{array}{c}\text { Sensitivity } \\
(\boldsymbol{\%})\end{array}$ & $\begin{array}{c}\text { Specificity } \\
(\boldsymbol{\%})\end{array}$ \\
\hline PLR & 123 & 0.751 & 72.7 & 70.3 \\
\hline NLR & 4 & 0.782 & 78.8 & 70.3 \\
\hline
\end{tabular}

PLR: Platelet Lymphocyte Ratio; NLR: Neutrophil Lymphocyte Ratio; AUC: Area Under the Curve

The ROC curve shown in (Table 4, Figure 1, Figure 2) was formed to determine sensitivity and specificity of PLR and NLR in discriminating stratification of GRACE score. The cutt-off value NLR of 4 and above had a sensitivity of $78.8 \%$ and specificity of $70.3 \%$, while cutt-off value PLR of 123 and above had a sensitivity of $72.7 \%$ and specificity of $70.3 \%$ to detect high risk of GRACE score.

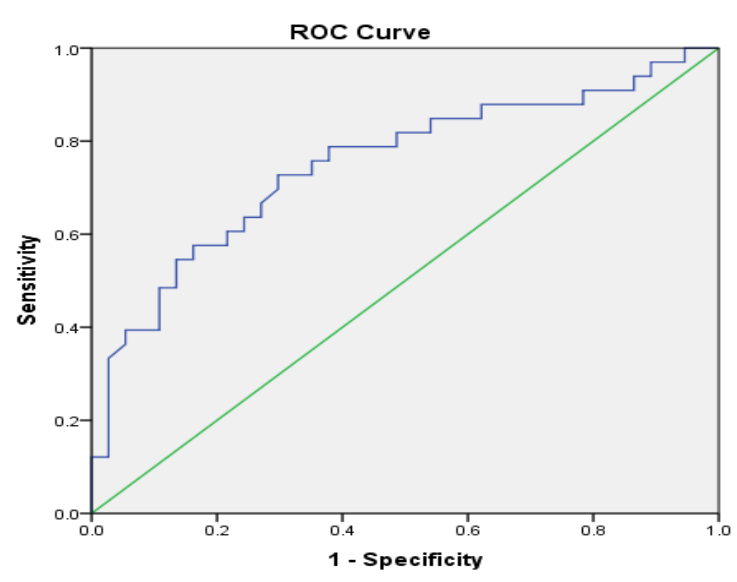

Figure 1:ROC Curve Analysis for PLR and GRACE score

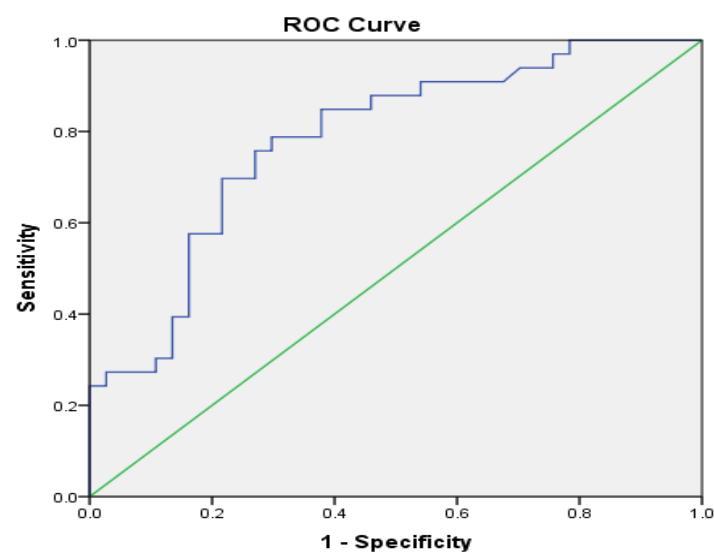

Figure 2: ROC Curve Analysis for NLR and GRACE score 


\section{DISCUSSION}

Current clinical guidelines recommend the GRACE score for risk stratification and assessing the prognosis of ACS. ${ }^{[6]}$ The GRACE score has good risk stratification for assessment and selection of invasive strategies early finds the best strategy for achieving and maintaining myocardial reperfusion. ${ }^{[5]}$ Several studies have shown that combining the GRACE score with other clinical and laboratory parameters can improve its predictive value. [12]

In this study, we found a positive correlation between PLR and NLR with the GRACE score of ACS patients. The PLR and NLR were both found significantly higher in the high risk GRACE score. The study of Zhou, found a positive correlation between GRACE score and PLR, where the combination of GRACE score and PLR was more effective in predicting incidence in ACS patients. ${ }^{[12]}$ Oncel et al. showed that the increase in NLR values had positive correlation with GRACE score. ${ }^{[14]}$

Inflammation has an important role in the initiation and progression of the atherosclerotic process. Inflammation is also known to play a role in all phases of ACS, which will affect the formation and rupture of atherosclerotic plaque. ${ }^{[14]}$ Neutrophils cause atherosclerotic plaque instability. In the early stages, neutrophils invasive endothelial cells and become active when they reach the tunica intima. Induces microvascular formation, making plaque more susceptible to rupture. ${ }^{[15]}$

Thrombus formation in the ruptured atherosclerotic plaque underlying the pathophysiology of ACS. The activation of platelet adhesion and aggregation plays an important role in this process. Platelets are activated by substances released from blood vessel wall cells. Platelets can release thromboxane and other mediators, increase adhesion and transmigration of monocytes, which can lead to increased inflammation and weaken plaque stability, then promote the development of atherosclerosis. [9] Platelets have an important role in the development, destabilization and rupture of atherosclerotic plaques, as well as in the formation of arterial fibrin-platelet thrombi that circulate on atherosclerotic plaques. ${ }^{[16]}$

Lymphocytes have been shown to modulate immunological responses at all stages of the atherosclerotic process. The systemic inflammatory response is characterized by a low lymphocyte count. ${ }^{[13]}$ Lymphocytes regulate the inflammatory response and play an antiatherosclerotic role where regulatory $\mathrm{T}$ cells have an inhibitory effect of atherosclerosis. Low lymphocyte counts as an early marker of physiological stress and systemic inflammation of myocardial ischemia. ${ }^{[17]}$

In this study, the ROC curve analysis found the cut-off value PLR of 123 and above had a sensitivity of $72.7 \%$ and specificity of $70.3 \%$, while cutt-off value NLR of 4 and above had a sensitivity of $78.8 \%$ and specificity of $70.3 \%$ to detect high risk GRACE score of ACS. Zhou, et al. found the combination of PLR and GRACE risk score could better predict long-term CVD events in patients with ACS. [12] Increased of PLR is associated with a worse prognosis of ACS based on the mechanism of atherosclerosis in ACS. ${ }^{[9]}$ Budzianowski et al., found cuff-off NLR of 4.9 and above had a sensitivity of $70 \%$ and a specificity of $65 \%$ in predicting mortality in ACS patients. ${ }^{[15]}$ Neutrophils as markers of inflammation and lymphocytes as markers of regulators. NLR is an indicator of systemic inflammation in ACS, integrating both of that as predictors and mortality of ACS. ${ }^{[15] ~[18]}$

The limitations of the study, this was a retrospective and single-center study that included a relatively small number of patients. This study only one-time measurement of admission full blood count and calculation of PLR and NLR were included in the analysis.

\section{CONCLUSION}

There is a significant association between PLR and NLR with GRACE score. The combination of PLR and NLR with 
GRACE score can provide an additional accurate predictor for ACS patients.

\section{Acknowledgement: None}

\section{Conflict of Interest: None}

\section{Source of Funding: None}

\section{Ethical Approval: Approved}

\section{REFERENCES}

1. Virani SS., Alonso A., Benjamin E.J., Bittencourt M.S., Callaway C.W., Carson A.P., et al. Heart Disease and Stroke Statistics-2020. Update: A Report From the American Heart Association. Circulation, Vol. 141, pp. 139-596. 2020.

2. Awan M.S., Daud M.Y., Khan M., Jehangiri A.U.R., Adnan, Jalil S. Usefulness Of Neutrophils To Lymphocytes Ratio For Predicting Troponin-I Elevation In Patients Presenting With Suspected Nste-Acute Coronary Syndrome. J Ayub Med Coll Abbottabad. 31 1(4):674-7. 2019.

3. Riskesdas K. Hasil Utama Riset Kesehata Dasar (RISKESDAS). J Phys A Math Theor 44(8):1-200.2018. [Online]. Available: http://arxiv.org/abs/1011.1669\%0A http://dx.doi.org/10.1088/17518113/44/8/08 5201\%0Ahttp://stacks.iop.org/1751$8121 / 44 / \mathrm{i}=8 / \mathrm{a}=085201$ ?key $=$ crossref.abc $74 \mathrm{c}$ 979a75846b3de48a5587bf708f.[Accessed : Jan, 2020].

4. Darmawan. Peran rasio neutrofil limfosit sebagai prediktor major adverse cardiac events tujuh hari dalam perawatan pasien sindrom koroner akut, Darmawan, FK UI, 2016.

5. Chotechuang Y., Phrommintikul A., Kuanprasert S., Muenpa R., Ruengorn C., Patumanond J., et al. GRACE score and cardiovascular outcomes prediction among the delayed coronary intervention after postfibrinolytic STEMI patients in a limited PCI-capable hospital. Open Hear. 7(1):e 001133. 2020.

6. Rahmani R., Majidi B., Ariannejad H., Shafiee A.. The value of the GRACE score for predicting the SYNTAX score in patients with unstable angina/non-ST elevation myocardial infarction. Cardiovasc Revascularization Med. 2019.
7. Verheugt F.W. The GRACE registry: How real-life evidence contributes to acute coronary syndrome guidelines. Eur Hear Journal, Suppl. 17:D29-31. 2015.

8. Tahto, E. et al. (2017) 'Neutrophil-tolymphocyte Ratio and Its Relation with Markers of Inflammation and Myocardial Necrosis in Patients with Acute Coronary Syndrome', Medical archives (Sarajevo, Bosnia and Herzegovina), 71(5), pp. 312315. doi: 10.5455/medarh.2017.71.312-315.

9. Li, W., Liu, Q. and Tang, Y. (2017) 'Platelet to lymphocyte ratio in the prediction of adverse outcomes after acute coronary syndrome: A meta-analysis', Scientific Reports. Nature Publishing Group, 7(January), pp. 1-9. doi: 10.1038/srep 40426.

10. Seyis, S., Gunay, S. and Rencuzoglu, I. (2017) 'Relationship between platelet to lymphocyte ratio and coronary angiography timing in patients with NSTEMI', Biomedical Research (India), 28(20), pp. 8963-8968

11. Shuvy M, Beeri G, Klein E, Cohen T, Shlomo N, Minha S, et al. Accuracy of the Global Registry of Acute Coronary Events (GRACE) Risk Score in Contemporary Treatment of Patients With Acute Coronary Syndrome. Can J Cardiol. 34(12):1613-7. 2018. [Online] Available from: https://doi.org/10.1016/j.cjca.2018.09.015. [Accessed : Mar, 2020].

12. Zhou, D. et al. (2016) 'Platelet-toLymphocyte Ratio Improves the Predictive Power of GRACE Risk Score for LongTerm Cardiovascular Events in Patients with Acute Coronary Syndrome', Cardiology (Switzerland), 134(1), pp. 3946. Doi

13. Acet, H. et al. (2016) 'Relationship between Hematologic Indices and Global Registry of Acute Coronary Events Risk Score in Patients with ST-Segment Elevation Myocardial Infarction', Clinical and Applied Thrombosis/Hemostasis, 22(1), pp. 60-68. doi: 10.1177/1076029614533145.

14. Oncel R.C., Ucar M., Karakas M.S., Akdemir B., Yanikoglu A., Gulcan A.R., et al. Relation of neutrophil-to-lymphocyte ratio with GRACE risk score to in-hospital cardiac events in patients with ST-segment elevated myocardial infarction. Clin Appl Thromb. 21(4):383-8. 2015. 
Baginda Yusuf Siregar et.al. Association of Platelet Lymphocyte Ratio (PLR) and Neutrophil Lymphocyte Ratio (NLR) with Global Registry of Acute Coronary Events (GRACE) score in acute coronary syndrome

15. Budzianowski J., Pieszko K., Burchardt P., Rze J. Review Article The Role of Hematological Indices in Patients with Acute Coronary Syndrome. 2017.

16. Kurtul, A. and Ornek, E. (2019) 'Platelet to Lymphocyte Ratio in Cardiovascular Diseases: A Systematic Review', Angiology, 70(9), pp. 802-818. doi: 10.1177/ 0003319719845186.

17. Núñez J., Miñana G., Bodí V., Núñez E., Sanchis J., Husser O., et al. Low Lymphocyte Count and Cardiovascular Diseases. 3226-33. 2011.

18. Chen C., Cong B.L., Wang M., Abdullah M., Wang X.L., Zhang Y.H., et al. Neutrophil to lymphocyte ratio as a predictor of myocardial damage and cardiac dysfunction in acute coronary syndrome patients. Integr Med Res. 7(2):192-9. 2018. [Online] Available from: https://doi.org/10.1016/j.imr.2018.02.006.

[Accessed : Jan, 2020].

How to cite this article: Siregar BY, Hasan R, Isnanta R. Association of Platelet Lymphocyte Ratio (PLR) and Neutrophil Lymphocyte Ratio (NLR) with Global Registry of Acute Coronary Events (GRACE) score in acute coronary syndrome. International Journal of Research and Review. 2021; 8(5): 1-6. DOI: https:// doi.org/10.52403/ijrr.20210501 